\title{
Determination of Safety Zones of Gas (NG and NGL) Pipelines
}

\author{
Huseyin Murat Cekirge \\ Department of Mechanical Engineering, the Grove School of Engineering, the City College of the City University of New York, New York, \\ USA
}

\section{Email address:}

hmcekirge@usa.net

\section{To cite this article:}

Huseyin Murat Cekirge. Determination of Safety Zones of Gas (NG and NGL) Pipelines. International Journal of Environmental Monitoring and Analysis. Special Issue: Environmental Social Impact Assessment (ESIA) and Risk Assessment of Crude Oil and Gas Pipelines.

Vol. 3, No. 6-1, 2015, pp. 9-17. doi: 10.11648/j.ijema.s.2015030601.12

\begin{abstract}
Quantitative analyses are necessary to find a safe passage of natural gas (NG) and natural gas liquids (NGL) pipelines. The paper is presenting the details of analyses and determination of safe zones around the gas pipelines. The methodology is a planning tool for determining the safe passages for gas pipelines. The methodologies are presented with examples. The necessary tools are also presented for these analyses.
\end{abstract}

Keywords: Safety Zones of Gas Pipelines, Safety Zones of Gas Pipelines, Safety Zones of NGL Pipelines

\section{Introduction}

The gas pipelines have various threats to environment [1] and [2], and for safety location of these pipelines, a quantitative analysis is a must to determine the safe passage of these pipelines through urban or other sensitive areas. The paper will present these analyses of fire and explosion for optimum design and proper location of the gas pipelines.

The understanding of any event threatening the area of by gas pipeline is necessary. The treat is the release of hydrocarbon from the pipeline, and this event event is called accident. The event of accident is defined as release or loss of material and/or energy contained in the pipeline. According to this definition, the event identified of this study is the leaking of hydrocarbons from NG and NGL pipeline. From the time when the accident occurs, it will be developed one or more threatening events, [3-11]. The type and amount of threatening events depend on the hydrocarbon in the pipeline:

- The characteristics of mass flow and pressure of the product at the site and time of breakage;

- Discharge conditions;

- The influence of the receiver on the generation of hazardous event; and

- The atmospheric conditions.

Additionally, in the development of threatening events NGL pipeline, involving the following characteristics:

- The medium (soil or water) receptor spill; and

- Spread features of spills in this medium.
Discharge conditions depend greatly on the size of the opening break. For this study, three types of releases are considered:

- Hole,

- Rupture; and

- Total Rupture which considers discharges through holes with diameters equivalent of $5 \%, 25 \%$ and $90 \%$ of the total diameter of the pipeline, respectively.

The accidents are:

Pool Fire: It happens if volatile vapors spilled product fractions within the upper and lower limits of flammability, contact with an ignition source, transferring sufficient energy to generate a fire of the whole mass of product is located a threatening event of interest. The resulting thermal radiation can generate a domino effect on vulnerable or chained elements adjacent area. The duration of the fire is related to the nature and quantity of fuel available to burn. The hydrocarbon fire may occur after the spill; in this case the spill can be confined by a dike or topography.

Jet Fire: It occurs when there is continuous leakage of highly pressurized flammable gas is turned near the point of the leak. A stream of fire generally produces thermal radiation continuous. The size of the affected area depends on the discharge rate of the gas, orientation and direction of the jet, and prevailing weather conditions at the time of the event.

Vapor Cloud Fire (Flash Fire or Flare): The flare 
corresponds to the rapid ignition of a vapor cloud. It occurs in the area between the lower and upper limits of flammability of vapor cloud, where appropriate air-vapor ratio in contact with flammable source ignition causes combustion of the available mass and generating thermal radiation. It is worth noting that the mass contained in the cloud is not enough to generate overpressure.

Unconfined Vapor Cloud Explosion (UVCE): It happens after the release of a large amount of flammable gas or vapor to atmosphere with ignition point at some distance from the exhaust, causing a sudden release and violent energy in waves of pressure. A necessary condition for cloud explosion gas pressure wave is caused by the presence of containment or obstruction, which favors high burning rates.

Geotechnical Stability: In the process of operation of the pipeline, it has implemented a maintenance program of the ROW (Right of Way) that reflects an assessment of the sensitivity. It has been done an initial assessment, with which they have taken the first steps to reduce the risk from the view of stability of the ROW, evaluations constantly updated to ensure that maintenance activities are executed in terms of reducing the risk of the pipeline. Infrastructure breakage may occur due to different factors or causes. It defined an assessment of integrity of the infrastructure from the standpoint of geotechnical stability, which has taken into account the constructive process, environmental conditions, and the phenomena of the natural environment and the level of risk. It represents the evaluated parameters of infrastructure to proximity population centers, difficult access to the site and nearby rivers with population.

To set the distance to which spilled material is extended must be calculated with consideration of evaporation of NGL in the cases NGL pipelines. Considering expansion to restricting water bodies, it is assumed that the product could stay twice as long at a distance of 70 kilometers, regardless of the product can stay on the banks of the stream water. In product storage conditions to form a pool, the product could have a longer residence time, in which case it would not be traveling on a spill route, and it may form 1000 barrels of a pool of 900 square meters. The evaporation rate would be approximately $4 \times 10^{-5}$ meters per hour, which means that the product would have greater permanence in a pool form if the product does not infiltrate.

\section{Threatening Events, Accidents}

\subsection{Determination of the Volume Flow from NG and NGL Pipelines}

The amount of the gas discharge from a NG pipeline is limited by the pipeline valves according to location. Given the types of breakage, valves before and after the cleavage site would isolate the sector. The volume is governed by the volume of gas content and pressure when a rupture happens, except for the first two minutes until the valves are being shut off. In minor breakages, this type of discharge is remained powered by the system's working pressure. The initial gas discharge flow will be defined mainly by initial system pressure at the time of breakage. This flow will decrease as gas is being dislodged as the internal pressure of gas equals to atmospheric pressure, at which discharge ceases. This applies to discharges due to a full and half break. Table 1 provides a summary of the results of valuation discharge from NG pipeline.

The final results of the analysis of consequences depend directly on the speed at which the product discharges to atmosphere. This speed is a function of operating pressure at the time of breakage in the case of the NG pipeline, and additionally for the NGL pipeline for transport, the speed of discharge depends on the maximum height difference of the product column. Initially, the release rate increases due to the pressure difference existing between the operating pressure at the point of rupture and pressure atmospheric. In the case of the spill or leak, the pressure difference in the discharge decreases to zero. At this moment the discharge starts to be governed only by the rate of pumping. For the case the NGL, by the static height of the column of liquid that may drain the site breakage. Discharge product tends to stabilize over the flow of normal operation, if the automatic closing valves do not act. When valves close in the NGL pipeline, the unloading is the product corresponding to the volume of content between the valves and the breaking point. Table 2 presents a summary assessment NGL discharge.

Table 1. The flow from the $N G$ pipeline.

\begin{tabular}{|c|c|c|c|c|c|c|c|c|}
\hline \multirow{2}{*}{ No. } & \multicolumn{2}{|c|}{ Location } & \multirow{2}{*}{$\begin{array}{l}\text { Level } \\
\text { meter }\end{array}$} & \multicolumn{2}{|c|}{ Diameter } & \multicolumn{3}{|l|}{ Flow Rate } \\
\hline & Part & $(\mathbf{k m}+\mathbf{m})$ & & inches & Pressure (psi) & Min. (kg/s) & Med. (kg/s) & Max. (kg/s) \\
\hline 1 & 0 & $0+000$ & 378.9 & 32 & 1812.5 & 12.4 & 61.8 & 222.7 \\
\hline 2 & 10 & $10+071$ & 423.9 & 32 & 1807.3 & 12.3 & 61.7 & 222.0 \\
\hline 3 & 20 & $19+854$ & 552.4 & 32 & 1802.2 & 26.3 & 131.5 & 473.5 \\
\hline 4 & 30 & $30+030$ & 705.3 & 32 & 1797.0 & 26.2 & 131.2 & 472.2 \\
\hline 5 & 40 & $39+999$ & 631.4 & 32 & 1791.8 & 26.2 & 130.8 & 470.8 \\
\hline
\end{tabular}


Table 2. The flow from the ruptured NGL pipeline.

\begin{tabular}{lllllllll}
\hline \multirow{2}{*}{ No. } & \multicolumn{2}{l}{ Location } & Level & DIAMETER & \multicolumn{2}{l}{ VOLUME } & \multicolumn{3}{l}{ SPILLED MATERIAL } \\
\cline { 2 - 8 } & Part & $\mathbf{( k m + m )}$ & meter & NOMINAL inches & Spill barrels & Min. Daily & Med. Hourly & Max. Minute \\
\hline 1 & 0 & $0+001$ & 382 & 14 & 717 & 2.5 & 2.4 & 11.9 \\
2 & 10 & $10+164$ & 405 & 14 & 383 & 1.4 & 1.3 & 6.5 \\
3 & 20 & $19+932$ & 548 & 14 & 2437 & 5.9 & 5.7 & 26.6 \\
4 & 30 & $30+084$ & 752 & 14 & 479 & 1.9 & 1.9 & 9 \\
5 & 40 & $40+047$ & 611 & 14 & 1409 & 3.2 & 3 & 14 \\
\hline
\end{tabular}

Table 3. Levels of Protection and involvement by thermal radiation, [12].

\begin{tabular}{ll}
\hline $\begin{array}{l}\text { THERMAL } \\
\text { RADIATION } \\
\left(\mathbf{K W} / \mathbf{m}^{2}\right)\end{array}$ & CONDITIONS \\
\hline$>37.5$ & Enough to cause damage to equipment. \\
\hline$>20.9$ & Zone $90 \%$ chance of death for longer exposure times of 30 seconds. \\
\hline$>14.50$ & $\begin{array}{l}\text { Zone } 50 \% \text { chance of death for longer exposure times of } 30 \text { seconds. } \\
\text { Do not expect staff in this area. }\end{array}$ \\
\hline $9.50-12.50$ & $\begin{array}{l}\text { Within this area, there is ignition of the wood subjected to flow heat for long time. Enough to melt plastic pipe intensity. Fatality due to third } \\
\text { degree burns after } 100 \text { seconds exposure will be developed. Second-degree burns after } 12 \text { seconds of exposure. }\end{array}$ \\
\hline $7.25-9.50$ & Caloric intensity that allows the exposure limit to some seconds, enough time to escape. \\
\hline $5-7.25$ & $\begin{array}{l}\text { Limit Zone 1\% chance of death for exposure times over 30 seconds. } \\
\text { Maximum exposure time of one (1) minute without appropriate protective clothing. First-degree burns after 30 seconds }\end{array}$ \\
\hline $1.6-5$ & $\begin{array}{l}\text { Maximum exposure time of three (3) minutes without protective clothing appropriate. First-degree burns after 120 seconds of exposure. The } \\
\text { consequences of the accident at this level have effects that, although perceived by the population, they do not justify the immediate } \\
\text { intervention of the protection measures on people. Limit caloric intensity zone in areas where they can be used emergency action lasting up to } \\
\text { several minutes for staff suitable clothes. }\end{array}$ \\
\hline$<1.6$ & $\begin{array}{l}\text { In this area, no damage from prolonged exposure. Area outside of the area corresponding safe area. Exposure times causing burns of first } \\
\text { second and third grade are given for people exposed to thermal radiation without any protection. }\end{array}$ \\
\hline
\end{tabular}

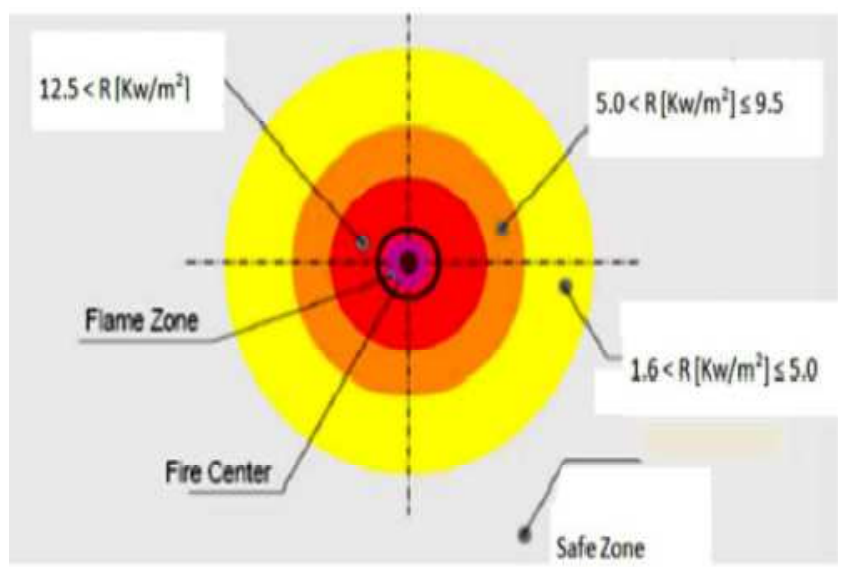

Figure 1. Safety zones of radiation, [2].

\subsection{Influence of Radiation}

Before calculating distances of influence and protection due to the occurrence of threatening events and product loss, it is necessary predetermined levels of interest of radiation. Interest levels are determined based on the effects they may have thermal radiation from the fire on people and materials. This study evaluates the distances in which percentages mortal 90, 50 and 1 percent by 30 seconds exposure to thermal radiation from the fire. Areas protection and influence can be established for emergency planning of fire is summarized in Table 3. The representation of these levels involvement can be seen in Figure 1.

\subsection{Vapor Cloud and Flare of NG and NGL}

The effects are caused by the thermal radiation flare is resulted mainly by direct contact of the flame with the person located within flammability limits NG and NGL cloud vapor. To this end, it states that the vapor cloud could ignite up to a maximum thermal situation from the vanishing point to the lower flammability limit (LFL); which is the distance at which the concentration of the cloud has diluted. The above area considers the death of everyone present; as the radiation produced by the flame of a hydrocarbon (above $170 \mathrm{~kW} / \mathrm{m}^{2}$ ), it is enough to cause death instantly. Additionally damage caused by direct contact of the flame, it must take into account the effects of radiation transmitted by convection to areas below the lower limit flammability. Table 4 describes involvement and protection by the flare event.

Table 4. Levels of involvement by blaze.

\begin{tabular}{ll}
\hline $\begin{array}{l}\text { Mortal area, Area } \\
\text { with clouds of } \\
\text { vapour } \\
\begin{array}{l}\text { concentration } \\
\text { above the LFL }\end{array}\end{array}$ & $\begin{array}{l}\text { Area where there should be no ignition sources, it is } \\
\text { assumed } 100 \% \text { probability of death of a person, as } \\
\text { long as this in the wind direction. }\end{array}$ \\
\hline & $\begin{array}{l}\text { Area whose closest distance to the vanishing point, } \\
\text { the sum of the distance at which the cloud is diluted } \\
\text { to LFL and the additional distance the probability of } \\
\text { death of } 1 \text { percent is expected due to the effects of } \\
\text { thermal radiation transmission. }\end{array}$ \\
\hline
\end{tabular}

Radiation level zones can be determined by softwares, [13-15]. These evaluations will lead obtaining protection and 
influence corridors where control and safety can be established according to the type of product and the conditions of discharge. Additionally each event is calculated under very conservative, where operating conditions are always maximum and type of discharge is always considered the greatest effect. The summary of results is presented for valuation in Tables 6 to 11 for various scenarios of NG and NGL pipeline accidents. As it is seen, results for the fire and flare conditions are presented and not for explosion. As a preventive measure; it is assumed that the distance from the area considered safe applies to flare, can be considered safe to cases of possible explosions.

Table 5. Influence distance $N G$ pipeline rupture minimum (5\%), in meters.

\begin{tabular}{|c|c|c|c|c|c|c|c|c|c|c|}
\hline \multirow[b]{2}{*}{ No. } & \multirow{2}{*}{$\begin{array}{l}\text { Campo } \\
\text { (No.) }\end{array}$} & \multirow[b]{2}{*}{ Location $(\mathbf{K m}+\mathbf{m})$} & \multicolumn{8}{|c|}{ RADIATION Minimum Rupture } \\
\hline & & & $\begin{array}{l}1.6 \\
\mathrm{Kw} / \mathrm{m}^{2}\end{array}$ & $\begin{array}{l}5.0 \\
\mathrm{Kw} / \mathrm{m}^{2}\end{array}$ & $\begin{array}{l}7.5 \\
\mathrm{Kw} / \mathrm{m}^{2}\end{array}$ & $\begin{array}{l}9.5 \\
\mathrm{Kw} / \mathrm{m}^{2}\end{array}$ & $\begin{array}{l}14.5 \\
\mathrm{Kw} / \mathrm{m}^{2}\end{array}$ & $\begin{array}{l}37.5 \\
\mathrm{Kw} / \mathrm{m}^{2}\end{array}$ & LFL & $\begin{array}{l}\text { SAFETY } \\
\text { ZONE }\end{array}$ \\
\hline 1 & 0 & $0+000$ & 72.4 & 39.9 & 34.3 & 31.5 & 26.9 & 18.9 & 43.0 & 60.3 \\
\hline 2 & 10 & $10+071$ & 72.2 & 39.8 & 34.3 & 31.4 & 26.9 & 18.9 & 43.0 & 60.2 \\
\hline 3 & 20 & $19+854$ & 109.2 & 60.2 & 51.8 & 47.5 & 40.6 & 28.6 & 64.9 & 90.9 \\
\hline 4 & 30 & $30+030$ & 109.0 & 60.1 & 51.7 & 47.4 & 40.5 & 28.5 & 64.8 & 90.8 \\
\hline 5 & 40 & $39+999$ & 108.8 & 60.0 & 51.6 & 47.3 & 40.5 & 28.5 & 64.7 & 90.6 \\
\hline
\end{tabular}

Table 6. Influence distance NG pipeline rupture medium (25\%), in meters.

\begin{tabular}{|c|c|c|c|c|c|c|c|c|c|c|}
\hline \multirow[b]{2}{*}{ No. } & \multirow[b]{2}{*}{ Segment No. } & \multirow{2}{*}{$\begin{array}{l}\text { Location } \\
(\mathbf{K m}+\mathbf{m})\end{array}$} & \multicolumn{8}{|c|}{ RADIATION Medium Rupture } \\
\hline & & & $\begin{array}{l}1.6 \\
\mathrm{Kw} / \mathrm{m}^{2}\end{array}$ & $\begin{array}{l}5.0 \\
\mathrm{Kw} / \mathrm{m}^{2} \\
\end{array}$ & $\begin{array}{l}.5 \\
\mathrm{Kw} / \mathrm{m}^{2}\end{array}$ & $\begin{array}{l}9.5 \\
\mathrm{Kw} / \mathrm{m}^{2}\end{array}$ & $\begin{array}{l}14.5 \\
\mathrm{Kw} / \mathrm{m}^{2}\end{array}$ & $\begin{array}{l}37.5 \\
\mathrm{Kw} / \mathrm{m}^{2}\end{array}$ & LFL & $\begin{array}{l}\text { SAFETY } \\
\text { ZONE }\end{array}$ \\
\hline 1 & 0 & $0+000$ & 171.8 & 94.7 & 81.5 & 74.7 & 63.9 & 44.9 & 102.2 & 143.1 \\
\hline 2 & 10 & $10+071$ & 171.6 & 94.6 & 81.4 & 74.6 & 63.8 & 44.9 & 102.1 & 142.9 \\
\hline 3 & 20 & $19+854$ & 254.4 & 140.3 & 120.7 & 110.6 & 94.6 & 66.6 & 151.4 & 211.9 \\
\hline 4 & 30 & $30+030$ & 254.1 & 140.1 & 120.6 & 110.5 & 94.5 & 66.5 & 151.1 & 211.6 \\
\hline 5 & 40 & $39+999$ & 253.7 & 139.9 & 120.4 & 110.3 & 94.3 & 66.4 & 150.9 & 211.3 \\
\hline
\end{tabular}

Table 7. Influence distance NG pipeline rupture maximum (90\%), in meters.

\begin{tabular}{|c|c|c|c|c|c|c|c|c|c|c|}
\hline \multirow[b]{2}{*}{ No. } & \multirow[b]{2}{*}{$\begin{array}{l}\text { Segment } \\
\text { No. }\end{array}$} & \multirow[b]{2}{*}{$\begin{array}{l}\text { Location } \\
(\mathbf{K m}+\mathbf{m})\end{array}$} & \multicolumn{8}{|c|}{ RADIATION Maximum Rupture } \\
\hline & & & $\begin{array}{l}1.6 \\
\mathrm{Kw} / \mathrm{m}^{2}\end{array}$ & $\begin{array}{l}5.0 \\
\mathrm{Kw} / \mathrm{m}^{2} \\
\end{array}$ & $\begin{array}{l}7.5 \\
\mathrm{Kw} / \mathrm{m}^{2} \\
\end{array}$ & $\begin{array}{l}9.5 \\
\mathrm{Kw} / \mathrm{m}^{2}\end{array}$ & $\begin{array}{l}14.5 \\
\mathrm{Kw} / \mathrm{m}^{2}\end{array}$ & $\begin{array}{l}37.5 \\
\mathrm{Kw} / \mathrm{m}^{2} \\
\end{array}$ & LFL & $\begin{array}{l}\text { SAFETY } \\
\text { ZONE } \\
\end{array}$ \\
\hline 1 & 0 & $0+000$ & 333.6 & 183.9 & 158.3 & 145 & 124 & 87.3 & 198.5 & 277.8 \\
\hline 2 & 10 & $10+071$ & 333.1 & 183.7 & 158.1 & 144.8 & 123.9 & 87.1 & 198.2 & 277.4 \\
\hline 3 & 20 & $19+854$ & 490.5 & 270.4 & 232.7 & 213.2 & 182.4 & 128.3 & 291.8 & 408.5 \\
\hline 4 & 30 & $30+030$ & 489.8 & 270 & 232.4 & 212.9 & 182.1 & 128.1 & 291.3 & 407.9 \\
\hline 5 & 40 & $39+999$ & 489 & 269.6 & 232 & 212.6 & 181.8 & 127.9 & 290.9 & 407.3 \\
\hline
\end{tabular}

Table 8. Influence distance NGL pipeline rupture minimum (5\%), in meters.

\begin{tabular}{|c|c|c|c|c|c|c|c|c|c|c|}
\hline \multirow[b]{2}{*}{ No. } & \multirow{2}{*}{$\begin{array}{l}\text { Segment } \\
\text { No. }\end{array}$} & \multirow[b]{2}{*}{ Location $(\mathbf{K m}+\mathbf{m})$} & \multicolumn{8}{|c|}{ RADIATION Minimum Rupture } \\
\hline & & & $\begin{array}{l}1.6 \\
\mathrm{Kw} / \mathrm{m}^{2}\end{array}$ & $\begin{array}{l}5.0 \\
\mathrm{Kw} / \mathrm{m}^{2}\end{array}$ & $\begin{array}{l}7.5 \\
\mathrm{Kw} / \mathrm{m}^{2}\end{array}$ & $\begin{array}{l}9.5 \\
K w / m^{2}\end{array}$ & $\begin{array}{l}14.5 \\
\mathrm{Kw} / \mathrm{m}^{2}\end{array}$ & $\begin{array}{l}37.5 \\
\mathrm{Kw} / \mathrm{m}^{2}\end{array}$ & LFL & $\begin{array}{l}\text { SAFETY } \\
\text { ZONE }\end{array}$ \\
\hline 1 & 0 & $0+001$ & 10.1 & 5.6 & 4.8 & 4.4 & 3.8 & 2.6 & 6.0 & 9.0 \\
\hline 2 & 10 & $10+164$ & 10.7 & 5.9 & 5.1 & 4.7 & 4.0 & 2.8 & 6.4 & 9.2 \\
\hline 3 & 20 & $19+932$ & 14.8 & 8.2 & 7.0 & 6.4 & 5.5 & 3.9 & 8.8 & 12.6 \\
\hline 4 & 30 & $30+084$ & 11.0 & 6.1 & 5.2 & 4.8 & 4.1 & 2.9 & 6.5 & 9.3 \\
\hline 5 & 40 & $40+047$ & 15.7 & 8.7 & 7.5 & 6.8 & 5.9 & 4.1 & 9.4 & 14.0 \\
\hline
\end{tabular}

Table 9. Influence distance NL pipeline rupture medium (25\%), in meters.

\begin{tabular}{|c|c|c|c|c|c|c|c|c|c|c|}
\hline \multirow[b]{2}{*}{ No. } & \multirow{2}{*}{$\begin{array}{l}\text { Segment } \\
\text { No. }\end{array}$} & \multirow[b]{2}{*}{ Location $(\mathbf{K m}+\mathbf{m})$} & \multicolumn{8}{|c|}{ RADIATION Medium Rupture } \\
\hline & & & $\begin{array}{l}1.6 \\
\mathrm{Kw} / \mathrm{m}^{2}\end{array}$ & $\begin{array}{l}5.0 \\
\mathrm{Kw} / \mathrm{m}^{2}\end{array}$ & $\begin{array}{l}7.5 \\
\mathrm{Kw} / \mathrm{m}^{2}\end{array}$ & $\begin{array}{l}9.5 \\
\mathrm{Kw} / \mathrm{m}^{2}\end{array}$ & $\begin{array}{l}14.5 \\
\mathrm{Kw} / \mathrm{m}^{2}\end{array}$ & $\begin{array}{l}37.5 \\
\mathrm{Kw} / \mathrm{m}^{2}\end{array}$ & LFL & $\begin{array}{l}\text { SAFETY } \\
\text { ZONE }\end{array}$ \\
\hline 1 & 0 & $0+001$ & 41.9 & 23.1 & 19.9 & 18.2 & 15.6 & 11.0 & 24.9 & 36.9 \\
\hline 2 & 10 & $10+164$ & 43.9 & 24.2 & 20.8 & 19.1 & 16.3 & 11.5 & 26.1 & 37.7 \\
\hline 3 & 20 & $19+932$ & 56.1 & 30.9 & 26.6 & 24.4 & 20.9 & 14.7 & 33.4 & 49.6 \\
\hline 4 & 30 & $30+084$ & 44.6 & 24.6 & 21.1 & 19.4 & 16.6 & 11.7 & 26.5 & 38.0 \\
\hline 5 & 40 & $40+047$ & 59.0 & 32.5 & 28.0 & 25.6 & 21.9 & 15.4 & 35.1 & 50.1 \\
\hline
\end{tabular}


Table 10. Influence distance NGL pipeline rupture maximum (90\%), in meters

\begin{tabular}{|c|c|c|c|c|c|c|c|c|c|c|}
\hline \multirow[b]{2}{*}{ No. } & \multirow[b]{2}{*}{ Segment No. } & \multirow[b]{2}{*}{ Location $(\mathbf{K m}+\mathbf{m})$} & \multicolumn{8}{|c|}{ RADIATION Maximum Rupture } \\
\hline & & & $1.6 \mathrm{Kw} / \mathrm{m}^{2}$ & $5.0 \mathrm{Kw} / \mathrm{m}^{2}$ & $\begin{array}{l}7.5 \\
\mathrm{Kw} / \mathrm{m}^{2} \\
\end{array}$ & $\begin{array}{l}9.5 \\
\mathrm{Kw} / \mathrm{m}^{2} \\
\end{array}$ & $\begin{array}{l}14.5 \\
\mathrm{Kw} / \mathrm{m}^{2}\end{array}$ & $\begin{array}{l}37.5 \\
\mathrm{Kw} / \mathrm{m}^{2} \\
\end{array}$ & LFL & SAFETY ZONE \\
\hline 1 & 0 & $0+001$ & 146.4 & 80.7 & 69.5 & 63.6 & 54.4 & 38.3 & 87.1 & 129.9 \\
\hline 2 & 10 & $10+164$ & 152.8 & 84.2 & 72.5 & 66.4 & 56.8 & 40.0 & 90.9 & 128.7 \\
\hline 3 & 20 & $19+932$ & 192.7 & 106.2 & 91.4 & 83.8 & 71.7 & 50.4 & 114.6 & 168.8 \\
\hline 4 & 30 & $30+084$ & 155.1 & 85.5 & 73.6 & 67.4 & 57.7 & 40.6 & 92.3 & 131.9 \\
\hline 5 & 40 & $40+047$ & 201.9 & 111.3 & 95.8 & 87.8 & 75.1 & 52.8 & 120.1 & 170.8 \\
\hline
\end{tabular}

Table 11. Levels of allocation and explosion protection [12].

\begin{tabular}{ll}
\hline RANGE PRESSURE, psig & DESCRIPTION \\
\hline 14.0 & $\begin{array}{l}\text { Maximum peak overpressure cannot develop a bang confined hydrocarbon vapours. This level of overpressure does not } \\
\text { cause death, but if it reaches a probability of impact } 45 \% \text { from ruptured eardrum. }\end{array}$ \\
\hline$>6.4$ & $\begin{array}{l}>6.4 \text { almost complete destruction of houses. Possible damage of tanks storage and processing equipment. Chance of } \\
\text { involvement } 10 \% \text { from ruptured eardrum. }\end{array}$ \\
\hline$>3.25$ & The eardrum rupture threshold (1\% probability) is presented this overpressure. \\
\hline$>3$ & Inside this area occur in severe damages on steel and masonry structures (industrial buildings). \\
\hline $0.4-2$ & Within this zone, the partial collapse of roofs occurs and walls of houses. \\
\hline$<0.4$ & Pressure levels sufficient to cause minor damage to structures, houses and buildings. \\
\hline
\end{tabular}

\subsection{Vapor Cloud Explosion NG and NGL}

The effects of an overpressure of an explosion which reaches the person can be fatal. If the person is away from the edge of the cloud bursts, the pressure is unable to cause death directly, but indirectly. This is the case of a pressure wave that can collapse a structure, which falls on a person. The death of the person is a result of a collapse of the structure would not be directly inevitable if the is in an open area. In the event of an explosion of a vapor cloud, the harm to the public is determined function overpressure levels, regardless of the exposure time. As people exposed to a peak overpressure do not have time to react or protect themselves. One effect of a pressure peak on people is ruptured eardrums, so the distances in which there are 50,10 and 1 percent probability is evaluated chance of this type of damage. [16-18]. Table 11 presents ranges overpressure characteristic values. In Figure 2. we can see the representation of these values.

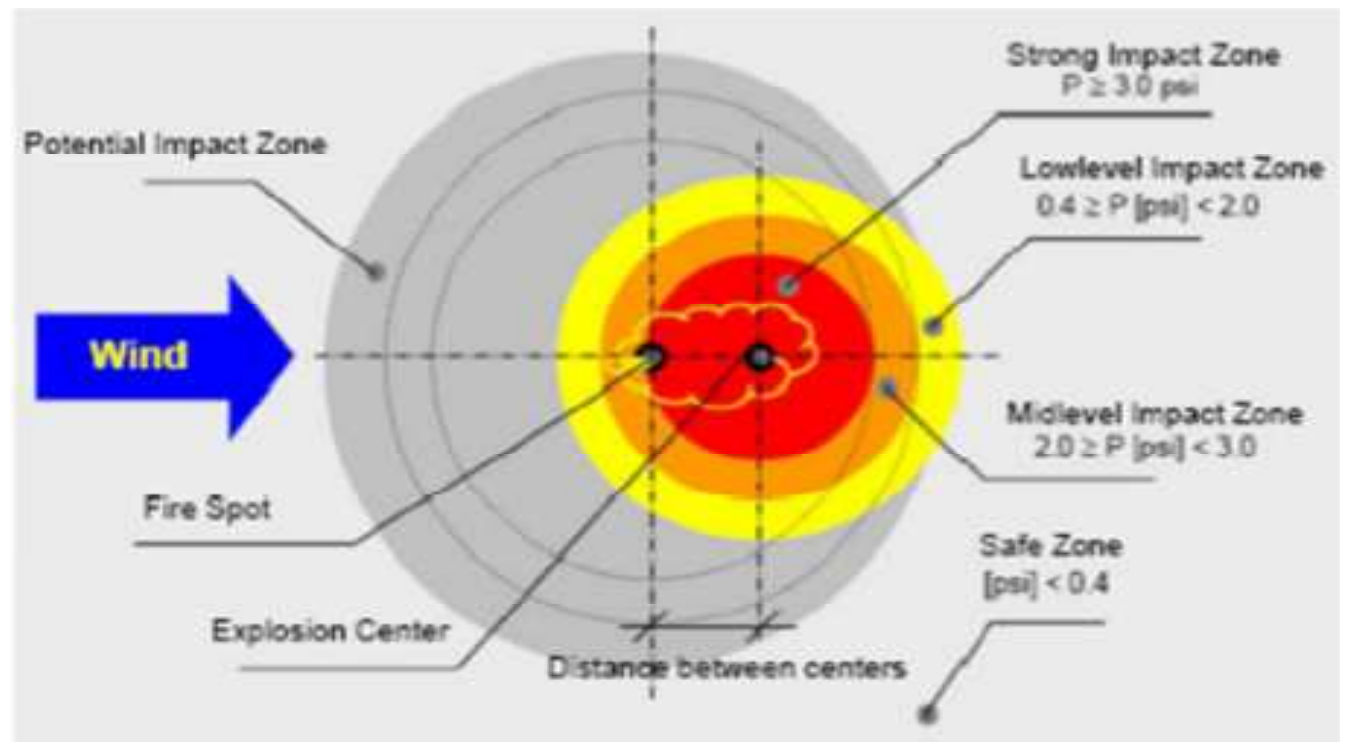

Figure 2. Impact areas by explosions, [2].

\section{Quantifying Threat}

\subsection{Spill Frequency Identification}

The threat of a leak or spill flammable product described in terms of the frequency of occurrence of threatening events affect the environment. In general, performing a quantitative risk analysis for transport operations of dangerous substances is conditional on an acceptable analysis of frequency of incident, for which historical data required for frequency calculations.

For the pipelines, 
is called base frequency; as this is obtained from international data, and therefore does not consider the situations of public order and social life that may affect the operation of the pipelines. Obtaining records frequency of leaks in transmission lines can be obtained from statistics reported by international control organizations. The wide range of international statistics can be summed up employing Equation 2 , which relates the calculation of the base frequency or base escape rate with the factors listed below:

Base Frequency * (Number of failure / (Length of the Pipeline*Year))

$$
=\mathrm{f}_{\text {age }} \mathrm{f}_{\text {product }} \mathrm{f}_{\text {diameter }} \mathrm{f}_{\text {zone }}
$$

Variables in Equation 2 are determined from the relationships presented in Tables 12 and 13, [19] and [20].

Table 12. Age factor pipe.

\begin{tabular}{ll}
\hline SIZE OF LEAK & $\mathbf{f}_{\text {age }}$ \\
\hline Small & $7.66+($ age -6.5$) * 1.18$ \\
Medium & $1.16+($ age -6.5$) * 0.179$ \\
Large & $0.776+($ age -6.5$) * 0.119$ \\
Total & $0.0621+($ age -6.5$) * 0.00954$ \\
\hline
\end{tabular}

Table 14. Obtaining the base frequency.

\begin{tabular}{|c|c|c|c|c|c|}
\hline Rupture & Age & Substance & Diameter & Area & Event / (km year) \\
\hline \multicolumn{6}{|c|}{ NG Pipeline } \\
\hline SMALL & 2.35 & 0.35 & 0.15 & 0.32 & $2.46 \mathrm{E}-05$ \\
\hline MEDIAN & 0.3545 & 0.35 & 0.15 & 0.32 & 3.72E-06 \\
\hline MAXIMUM & 0.2405 & 0.35 & 0.15 & 0.32 & $2.52 \mathrm{E}-06$ \\
\hline \multirow[t]{3}{*}{ Total } & 0.01917 & 0.35 & 0.15 & 0.32 & $2.01 \mathrm{E}-07$ \\
\hline & & & & Total frequency & 3.11E-07 \\
\hline & \multicolumn{5}{|c|}{ NGL pipeline } \\
\hline MEDIAN & 0.3545 & 0.35 & 0.89 & 0.32 & 2.19E-05 \\
\hline MAXIMUM & 0.2405 & 0.35 & 0.89 & 0.32 & $1.48 \mathrm{E}-05$ \\
\hline \multirow[t]{2}{*}{ Total } & 0.01917 & 0.35 & 0.89 & 0.32 & $1.18 \mathrm{E}-06$ \\
\hline & & & & Total Frequency & $1.83 * 10-4$ \\
\hline
\end{tabular}

Table 15. Base frequency distribution according to the size of rupture.

\begin{tabular}{ll}
\hline Size of the Rupture & Percentage of occurrence \\
\hline Leak & 89.0 \\
Hole & 10.0 \\
Rupture & 1.0 \\
\hline
\end{tabular}

\subsection{Estimation of Probabilities Event}

The frequency of occurrence of a threatening event is determined mainly by the probability of existence of ignition sources that create such events and operating conditions of the discharge. The ignition probability depends on three factors namely:

- Mass involved in the event;

- Temperature of the substance released; and

- Existence of ignition source.
Table 13. Factors determining base frequency.

\begin{tabular}{l|l|l|l|l}
\hline Material & $\mathbf{f}_{\text {product }}$ & $\mathbf{f}_{\text {diameter }}$ & Zone & $\mathbf{f}_{\text {zone }}$ \\
\hline Crude & 1 & & $\begin{array}{l}\text { Open } \\
\text { Area }\end{array}$ & 0.32 \\
\cline { 1 - 1 } White Products & 0.46 & $(103.5-2.9 * \phi) / 71$ & Urban & 1 \\
\hline NG/NGL & 0.35 & & \\
\hline
\end{tabular}

$\phi=$ Diameter, inches

Table 14 provides the base frequency to the operating conditions and layout the pipeline. All previous calculations considered the value of 0.35 for $\mathrm{f}_{\text {producto }}$, assigned to transport of NG and NGL or a similar product, and considering the greater part of the path in rural areas, through a pipe 14" and 32" (crude oil pipeline and gas pipeline, respectively) with an operating age of 2 years.

The values reported above are totally statistics from other systems within the past two years of operation. They have been presented in the 5 events in the pipeline operation, which determines spills of $220 \mathrm{~km}$ of NGL pipeline in two years; it gives a frequency of $1.14 * 10^{-2}$ spills / Km Year. In order to make an adjustment real and actual frequency are averaged with the statistics in the final risk assessment. The frequency versus escape breaks can be set, and the distribution is presented in Table 15. 


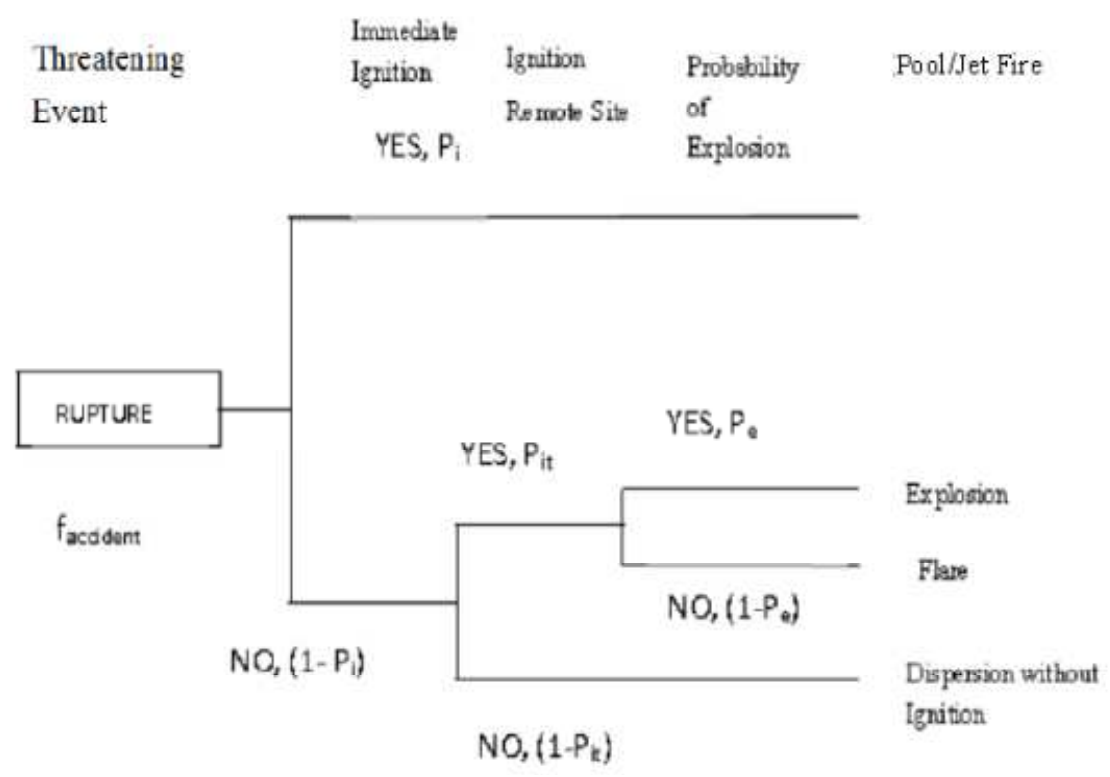

Figure 3. Threating tree analysis of a rupture.

Therefore, the frequency of occurrence of events, fire and flame, $f_{\text {FIRE }}$ and $f_{F L}$, respectively, will be given as

$$
\begin{aligned}
\mathrm{f}_{\text {fire }} & =\mathrm{f}_{\text {accident }} \mathrm{P}_{\mathrm{i}} \\
\mathrm{f}_{\mathrm{fl}} & =\mathrm{f}_{\text {accident }}\left(1-\mathrm{P}_{\mathrm{i}}\right) \mathrm{P}_{\text {it }}
\end{aligned}
$$

where;

$\mathrm{P}_{\mathrm{fl}}=\left(1-\mathrm{P}_{\mathrm{i}}\right) \mathrm{P}_{\mathrm{it}}$, Probability of flame;

$\mathrm{P}_{\mathrm{i}}=$ Probability of ignition of the discharge phase;

$\mathrm{P}_{\mathrm{it}}=$ Probability of delayed ignition; and

$\mathrm{P}_{\mathrm{e}}=$ Probability of explosion.

\subsection{Calculating the Probability of Ignition}

Ignition corresponds to source of energy that can make an escape gas or vapor generated by a flammable liquid materialize to a fire. The ignition can occur both at the point of escape or any distance from this point. Estimated values of the probability of ignition, whether as ignition or specific ignition sources, estimated for leaks flammable fluids (gases or liquids), can be seen in Table 16, [21] and [22].

Table 16. Estimation of the probability of ignition.

\begin{tabular}{lcc}
\hline Escape from Rupture & GAS & LIQUID \\
\hline SMALL $(<1 \mathrm{Kg} / \mathrm{s})$ & 0.01 & 0.01 \\
MEDIUM $(1-50 \mathrm{Kg} / \mathrm{s})$ & 0.07 & 0.03 \\
MAXIMUM $(>50 \mathrm{Kg} / \mathrm{s})$ & 0.30 & 0.08 \\
\hline
\end{tabular}

\section{Assessment of Individual Risk}

\subsection{Risk Estimation}

Once, the frequencies of occurrence of threatening events are obtained, then distances at which the highest probability of death can be calculated. The maximum individual risk for each scenario considered can be calculated. Subsequently, this level risk can be compared with other daily activities that involve risk. The maximum individual risk is the increased chance of death of a person exposed to a threat, within a period of time. The calculation of the maximum individual risk at (x, y) considers all threatening events that can be generated by fires and flares.

For the calculation of the maximum individual risk, the following probabilities are taken into account for simplifications:

- The probability of wind direction in the sense that it can affect a person is 0.5 . This considering is that the wind is in all directions.

- The probability of death by contacting jet flame is the maximum (100\%), the lower limit of this distance is the distance of flammability of flare of the event; and it is the probability of death contact direct to the jet fire; radiation is above $37.5 \mathrm{~kW} / \mathrm{m}^{2}$.

As each threatening event generates a maximum distance; the final distance taken into account for the highest individual risk is lower than risk of all other events that is considering the three types of breaks, fire, flame, and explosion. The calculation of the maximum individual risk is given by;

$$
\begin{gathered}
\mathrm{R}_{\text {xyij }}=\mathrm{f}_{\text {Exposition }} \mathrm{f}_{\mathrm{Di}} \mathrm{P}_{\mathrm{Iji}} \mathrm{L}_{\text {SECTIONji }} \mathrm{P}_{\text {Wind_direction }} \\
R_{x y}=\sum_{i} \sum_{j} R_{x y i j}
\end{gathered}
$$

$\mathrm{i}=$ types of failure considered.

$\mathrm{j}=$ type of fire (pool fire and flare)

$f_{D j}=($ number of spills or leaks / year- Km); base frequency by type of spill;

$\mathrm{x}, \mathrm{y}=$ location of break $\mathrm{j}$;

$\mathrm{P}_{\mathrm{Iji}}=$ probability according to type of threat $(\mathrm{j})$, according to the type of failure (i).

$\mathrm{L}_{\text {SECTIONji }}$ length in kilometers of pipelines considered for the study, and it is section is determined based on the maximum and both sides or double sides of the corridor of hazard generated any of the events (j) point $\mathrm{x}, \mathrm{y}$. 
Table 17. Individual Risk Levels, by considering Equation 5, $f_{\text {Exposition }}=1$.

\begin{tabular}{|c|c|c|c|c|c|c|}
\hline FREQUENCY & STATISTICS, $\mathbf{f}_{\mathrm{Di}}$ & PERCENT LEAK & $\operatorname{Pr} r_{\text {EVEnT }}, P_{\mathrm{Iji}}$ & $\begin{array}{l}\text { DISTANCE, } \\
\text { L }_{\text {SECTIONji }}\end{array}$ & $\begin{array}{l}\text { Probability of Wind } \\
\text { Direction, } \mathbf{P}_{\text {Wind_direction }}\end{array}$ & $\begin{array}{l}\text { Individual } \\
\text { Risk, } \mathbf{R}_{\text {xyij }}\end{array}$ \\
\hline \multicolumn{7}{|l|}{$\mathrm{Km} 08+800$} \\
\hline & $3.11 \mathrm{E}-05$ & 0.89 & 0.07 & 62.5 & 0.125 & $1.51 \mathrm{E}-08$ \\
\hline & $3.11 \mathrm{E}-05$ & 0.89 & 0.0651 & 45 & 0.125 & $1.01 \mathrm{E}-08$ \\
\hline & $3.11 \mathrm{E}-05$ & 0.1 & 0.07 & 230.6 & 0.125 & $6.28 \mathrm{E}-09$ \\
\hline & $3.11 \mathrm{E}-05$ & 0.1 & 0.0651 & 229 & 0.125 & $5.80 \mathrm{E}-09$ \\
\hline & $3.11 \mathrm{E}-05$ & 0.01 & 0.07 & 314 & 0.125 & $8.54 \mathrm{E}-10$ \\
\hline & $3.11 \mathrm{E}-05$ & 0.01 & 0.0651 & 1632 & 0.125 & 4.13E-09 \\
\hline TOTAL & & & & & & 4.23E-08 \\
\hline \multicolumn{7}{|l|}{$\mathrm{Km} 50+600$} \\
\hline & $3.11 \mathrm{E}-05$ & 0.89 & 0.07 & 61.4 & 0.125 & 1.49E-08 \\
\hline & $3.11 \mathrm{E}-05$ & 0.89 & 0.0651 & 43.6 & 0.125 & $9.82 \mathrm{E}-09$ \\
\hline & $3.11 \mathrm{E}-05$ & 0.1 & 0.07 & 240.9 & 0.125 & $6.56 \mathrm{E}-09$ \\
\hline & $3.11 \mathrm{E}-05$ & 0.1 & 0.0651 & 235 & 0.125 & $5.95 \mathrm{E}-09$ \\
\hline & $3.11 \mathrm{E}-05$ & 0.01 & 0.07 & 365 & 0.125 & $9.93 \mathrm{E}-10$ \\
\hline & $3.11 \mathrm{E}-05$ & 0.01 & 0.0651 & 2058 & 0.125 & $5.21 \mathrm{E}-09$ \\
\hline TOTAL & & & & & & $4.34 \mathrm{E}-08$ \\
\hline
\end{tabular}

$\mathrm{P}_{\text {Wind direction }}=$ probability of wind direction to the person located at the point $\mathrm{x}, \mathrm{y}$ and

$\mathrm{f}_{\text {Exposition }}=$ factor determines the probability that the person at the point $(\mathrm{x}, \mathrm{y})$, who is exposed to the event of danger averaged according day and night.

The person is exposed to the event of hazard; the situation is averaged day and night. For calculating the exposure factor;

$$
f_{\text {Exposition }}=\left(P_{\text {ED }}\left(1-P_{\text {OUT }}\right) \underset{P_{\text {REDUCTION }}+P_{\text {EN }} P_{\text {FIRE }}\left(1-P_{\text {OUT }}\right)}{\left.P_{\text {REDUCTION }}\right) / 2}\right.
$$

where;

$\mathrm{f}_{\text {Exposition }}=$ The probability that the person is at $\mathrm{x}, \mathrm{y}$;

$\mathrm{P}_{\mathrm{ED}}=$ Probability that the person is on site daily, is considered as 0.69 ;

$\mathrm{P}_{\mathrm{EN}}=$ Probability that the person is in the room at night, is considered as 1.0 ;

$\mathrm{P}_{\text {OUT }}=$ Probability that the person is outside the house, is considered as 0.35 ; and

$\mathrm{P}_{\text {REDUCTION }}=$ Reduction factor generated by being the person inside the house and as a conservative factor, 0.45

The above values determine an exposure factor as 0.54 . Table 17 presents the maximum individual risk levels calculated for the points more frequent events.

\subsection{Analysis of Results}

According to the information presented in Table 17, the presence of the discharge generates an individual risk with values between $4.23 * 10^{-8}$ and $4.34 * 10^{-8}$ deaths / year to the areas adjacent to the corridor line.

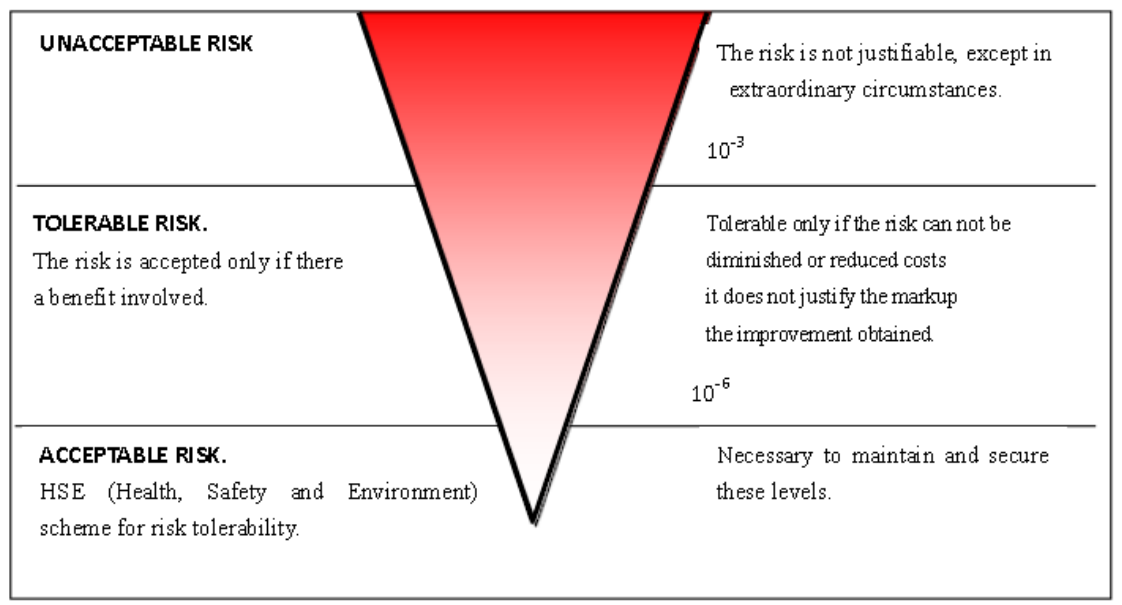

Figure 4. Individual risk levels.

Since there is no official regulation to evaluate and determine levels tolerable and acceptable risk, in this study a comparison is established with national and international statistics on usual pre-existing risks, as well as levels of acceptability adopted by different countries. By considering general HSE (Health, Safety and Environment) rules, the schematic in Figure 4 sets out the risk levels identified where more than $10^{-3}$ value is an intolerable risk to working activities considered "dangerous"; for a person outside the industry limit tolerability of risk decreases to $10^{-4}$. Values between $10^{-3}$ and $10^{-6}$ are considered tolerable; only if necessary steps are taken to reduce risks to levels that are reasonably practical. Values less than $10^{-6}$ are considered negligible, and the risk classified as acceptable. Based on the criteria of Figure 4 and the risk 
levels reported in Table 17 identify that all points in this section of the pipeline, have levels of tolerable risk.

\section{Conclusions}

The methodology is presented is detailed analysis of determinations of safety zones of NG and NGL pipelines for accidents. The analysis is covering fire, flame and explosions. In addition to these analyses, estimation individual risk and safety are discussed.

This report is guidance to design the ROW for a gas pipeline; however a system must be established to determine safety zones during accidents by considering prevailing topographic, environmental and meteorological conditions. This is necessary to minimize the fatalities.

\section{References}

[1] Huseyin Murat Cekirge. Qualitative Risk of Gas Pipelines. American Journal of Energy Engineering. Vol. 3, No.3, 2015, pp. 53-56. doi: 10.11648/j.ajee.20150303.14

[2] H. M. Cekirge, Safety Analysis, Maltepe Uni., Internal Rep. 1/1, Istanbul, 2010.

[3] Guidelines for Chemical Process Quantitative Risk Analysis. AICHE. Second Edition.2000.

[4] FEMA, Emergency Response Guidebook, 2008.

[5] FEMA, DOT, and EPA, Handbook of Chemical Hazards Analysis Procedures, US Environmental Protection Agency, US Department of Transportation, and the Federal Emergency Management Agency, 1989.

[6] United States Environmental Protection Agency (EPA), Evaluation of Dense Gas Simulation Models, Draft, EPA 450/4-90, United States Environmental Protection Agency, September 1990.

[7] J. L. Kennedy, Oil and Gas Pipeline Fundamentals, Pinacle Books, Richford, VT, 1984.

[8] Rizkalla, M. (editor), Pipeline Geo-Environmental Design and Geohazard Management, ASME, 2008.

[9] W. K. Muhlbauer, Pipeline Risk Management Manual: Ideas, Techniques, and Resources, Gulf Publishing Services, Burlington, Mass., 2004
[10] GIUSP, The Gas Industry Unsafe Situations Procedures-Edition 6, Including 1 \& 2, 2 April 2012.

[11] Young-Do Jo and Daniel A. Crowl, Individual risk analysis of high-pressure natural gas pipelines, Journal of Loss Prevention in the Process Industries, Volume 21, Issue 6, Pages 589-595, November 2008.

[12] Guidelines for Chemical Process Quantitative Risk Analysis. AICHE, Second Edition, 2000.

[13] Steve Lewis, An Overview of Leading Software Tools for QRA, American Society of Safety Engineers -Middle East Chapter (161), $7^{\text {th }}$ Professional Development Conference \& Exhibition, Kingdom of Bahrain, www.asse-mec.org, March 18-22, 2005.

[14] OGB, Risk Assessment Data Directory, International Association of Oil \& Gas Producers, Report No. 434 - 7, March 2010.

[15] http://www.risk-support.co.uk/consequence_modelling.ht m, 2015.

[16] R. Michael Reynolds, ALOHA (Areal Locations of Hazardous Atmospheres) 5.0 Theoretical Description, NOAA Technical Memorandum NOS ORCA-65, Seattle, Washington 98115, August 1992.

[17] United States Environmental Protection Agency (EPA), ALOHA ${ }^{\circledR}$ ArealLocations of Hazardous Atmospheres), User's Manual, United States Environmental Protection Agency, Office of Emergency Management, Washington, D.C. and National Oceanic and Atmospheric Administration, Office of Response, Seattle, Washington, February 2006

[18] United States Environmental Protection Agency (EPA), Download of ALOHA, Version 5.4, http:www.epa.Rov/ceppo/cameo/request.htm. Accessed September 2006.

[19] J. R. Taylor, Review of Failure Rate Data for Risk Analysis, 1998.

[20] J. R. Taylor, Risk Analysis for Process Plant, Pipelines and Transport, E \& FN Spon, New York, 1994 Guidelines for Chemical Process Quantitative Risk Analysis. CCPS, AIChE, 1989.

[21] A. W. Cox, Frank P. Lees and M. L. Ang, Classification of Hazardous Locations, IchemE, 1990.

[22] Frank Lees, Loss Prevention in the Process Industries. Hazard Identification, Assessment and Control. 1996. 